\title{
ReSEARChArticle
}

\section{New record occurrence of mycosphaerella leaf spot of eucalyptus in Himachal Pradesh}

\author{
SUNITA CHANDEL AND VIJAY KUMAR
}

\section{SUMMARY}

A study on occurrence and distribution of Mycosphaerella leaf spot of Eucalyptus was conducted at Solan district of Himachal Pradesh during August, 2015 to December, 2015. On the basis of the morphological characteristics, the fungus was identified as Mycosphaerella cryptica and Mycosphaerella marksii which produced symptoms like necrotic spots and patches on leaves and presence of crinkled and distorted foliage. Ascopores of M. cryptica and M. marksii are hyaline, with one septum, fusiform to tunecate and whose size varies from 12-16 x 2-4 $\mu \mathrm{m}$ and 11-14 x 2-3 $\mu \mathrm{m}$, respectively.

Key Words : Mycosphaerella spp., Eucalyptus, Conidia

How to cite this article : Chandel, Sunita and Kumar, Vijay (2016). New record occurrence of mycosphaerella leaf spot of eucalyptus in Himachal Pradesh. Internat. J. Plant Sci., 11 (2): 288-290, DOI: 10.15740/HAS/IJPS/11.2/288-290.

Article chronicle : Received : 14.03.2016; Revised : 09.05.2016; Accepted : 15.06.2016 